\title{
Prevalence, Patterns, Association with Biofilm Formation, Effects on Milk Quality and Risk Factors for Antibiotic Resistance of Staphylococci from Bulk-Tank Milk of Goat Herds
}

\author{
Daphne T. Lianou ${ }^{1}$, Efthymia Petinaki ${ }^{2}$, Peter J. Cripps ${ }^{1}$, Dimitris A. Gougoulis ${ }^{1}$ (D), Charalambia K. Michael ${ }^{1}$, \\ Katerina Tsilipounidaki ${ }^{2}$ D, Anargyros Skoulakis ${ }^{2}$, Angeliki I. Katsafadou ${ }^{3}$, Natalia G. C. Vasileiou ${ }^{4}$, \\ Themis Giannoulis ${ }^{4}$ (D), Eleni I. Katsarou ${ }^{1}$, Chrysoula Voidarou ${ }^{5}$, Vasia S. Mavrogianni ${ }^{1}$, Mariangela Caroprese ${ }^{6}$ \\ and George C. Fthenakis ${ }^{1, *}$
}

check for updates

Citation: Lianou, D.T.; Petinaki, E.; Cripps, P.J.; Gougoulis, D.A.; Michael, C.K.; Tsilipounidaki, K.; Skoulakis, A.; Katsafadou, A.I.; Vasileiou, N.G.C.; Giannoulis, T.; et al. Prevalence, Patterns, Association with Biofilm Formation, Effects on Milk Quality and Risk Factors for Antibiotic Resistance of Staphylococci from Bulk-Tank Milk of Goat Herds. Antibiotics 2021, 10, 1225. https:// doi.org/10.3390/antibiotics10101225

Academic Editor: Helena Felgueiras

Received: 17 September 2021

Accepted: 6 October 2021

Published: 8 October 2021

Publisher's Note: MDPI stays neutral with regard to jurisdictional claims in published maps and institutional affiliations.

Copyright: (C) 2021 by the authors. Licensee MDPI, Basel, Switzerland. This article is an open access article distributed under the terms and conditions of the Creative Commons Attribution (CC BY) license (https:/ / creativecommons.org/licenses/by/ $4.0 /)$.
1 Veterinary Faculty, University of Thessaly, 43100 Karditsa, Greece; dlianou@vet.uth.gr (D.T.L.); peterjohncripps@gmail.com (P.J.C.); dgoug@vet.uth.gr (D.A.G.); cmichail@vet.uth.gr (C.K.M.); elekatsarou@vet.uth.gr (E.I.K.); vmavrog@vet.uth.gr (V.S.M.)

2 University Hospital of Larissa, 41110 Larissa, Greece; petinaki@med.uth.gr (E.P.); tsilipoukat@gmail.com (K.T.); skulakis@gmail.com (A.S.)

3 Faculty of Public and One Health, University of Thessaly, 43100 Karditsa, Greece; agkatsaf@vet.uth.gr

4 Faculty of Animal Science, University of Thessaly, 41110 Larissa, Greece; vasileiounat@gmail.com (N.G.C.V.); themisgia@gmail.com (T.G.)

5 Department of Agriculture, University of Ioannina, 47132 Arta, Greece; xvoidarou@uoi.gr

6 Department of Agriculture, Food, Natural Resources and Engineering (DAFNE), University of Foggia, 71122 Foggia, Italy; mariangela.caroprese@unifg.it

* Correspondence: gcf@vet.uth.gr

Abstract: The objectives of this work were to study the prevalence and the patterns of antibiotic resistance of staphylococcal isolates from bulk-tank milk of goat herds across Greece, to assess possible associations of the presence of antibiotic resistance with the quality of milk in these herds and to evaluate herd-related factors potentially associated with the presence of antibiotic resistance among these staphylococcal isolates. A cross-sectional study was performed on 119 goat herds in Greece. Bulk-tank milk samples were collected for bacteriological examination; staphylococcal isolates were evaluated for resistance to 20 antibiotics. Oxacillin-resistant, resistant to at least one antibiotic, and multi-resistant staphylococcal isolates were recovered from $5.0 \%, 30.3 \%$, and $16.0 \%$ of herds, respectively. Of 80 isolates, $7.5 \%$ were resistant to oxacillin, 50.0\% were resistant to at least one antibiotic and $27.5 \%$ were multi-resistant. Resistance was seen more frequently among coagulase-negative staphylococci (59.3\%) than among Staphylococcus aureus (23.8\%). Resistance was more frequent against penicillin and ampicillin (41.3\% of isolates) and fosfomycin (27.5\%). No association was found with biofilm formation by staphylococci. For recovery of oxacillin-resistant isolates, the presence of working staff in the herds emerged as a significant factor; respective factors for the isolation of staphylococci resistant to at least one antibiotic were part-time farming and high (>10) number of systemic disinfections in the farm annually. The same three factors concurrently were also identified to be significant for the recovery of multi-resistant isolates.

Keywords: bulk-tank milk; mastitis; methicillin; milk; goat; somatic cell counts; staphylococcus; tetracycline; total bacterial counts

\section{Introduction}

In Greece, goat farming for milk production is a significant sector of the agricultural industry. Goat milk production in the country amounted to 143,270,500 L in 2019 [1], which accounts for $10 \%$ of European and $3 \%$ of world goat milk production [2]. The product is consumed as a drink or used in cheese manufacturing. Among the various cheese 
types produced, an important part is exported (e.g., 'feta' cheese), which indicates the international significance of the goat farming industry in the country.

The quality of raw milk is important because it contributes to the quality of cheese and is significant for public health. Among the various factors that account for the quality of raw goat milk, antibiotic-resistant bacteria are of prime importance.

Staphylococci are frequently recovered from bulk-tank milk of goat herds [3-5]. Most previous studies that examined staphylococcal isolates from bulk-tank milk of goat farms, evaluated mostly methicillin-resistance, with variable results. For example, in Pakistan, Altaf et al. [6] reported that $19 \%$ of 122 S. aureus recovered from the milk of goats showed resistance to methicillin, whilst Caruso et al. [7] reported that they recovered only one such isolate from bulk-tank milk of 66 goat farms in Italy. In research that evaluated more antibiotics, the proportion of resistant isolates was found to be up to $100 \%$ in Brazil [8] and Jordan [9]. Thus far, all studies related to the resistance of staphylococci from goat milk have focused on the patterns of resistance of the staphylococcal isolates; herd management factors that are potentially associated with the development of resistance have not been thoroughly studied.

The objectives of this work were (a) to study the prevalence and the patterns of antibiotic resistance of staphylococcal isolates from bulk-tank milk of goat herds across Greece, (b) to assess possible associations of the presence of antibiotic resistance with the quality of milk in these herds, and (c) to evaluate herd-related factors potentially associated with the presence of antibiotic resistance among these staphylococcal isolates.

\section{Results}

\subsection{Staphylococcal Recovery and Presence of Antibiotic Resistance}

In total, staphylococci were recovered from bulk-tank milk samples from 75 herds (63.0\%, 95\% CI: 54.1-71.2\%). Of these, Staphylococcus aureus was isolated from samples from $21(17.6 \%)$ herds and coagulase-negative staphylococci were isolated from samples from $54(45.4 \%)$ herds. A total of 80 staphylococcal isolates were recovered (21 S. aureus and 59 coagulase-negative staphylococci) (Table 1).

Table 1. Frequency of staphylococcal species recovered from bulk-tank milk of 119 goat herds in Greece.

\begin{tabular}{|c|c|c|c|c|}
\hline \multirow[b]{2}{*}{ Staphylococcal Species } & \multicolumn{4}{|c|}{ Frequency of Staphylococcal Isolates } \\
\hline & All Isolates ${ }^{1}$ & Resistant Isolates ${ }^{2,3}$ & $\begin{array}{l}\text { Multi-Resistant } \\
\text { Isolates }^{3}\end{array}$ & $\begin{array}{l}\text { Biofilm-Forming } \\
\text { Isolates }^{3}\end{array}$ \\
\hline Staphylococcus aureus & $21(0.263)$ & $5(0.238)$ & $0(0.000)$ & $17(0.810)$ \\
\hline Staphylococcus equorum & $11(0.138)$ & $9(0.818)$ & $8(0.727)$ & $8(0.727)$ \\
\hline Staphylococcus simulans & $9(0.113)$ & $1(0.111)$ & $0(0.000)$ & $6(0.667)$ \\
\hline Staphylococcus capitis & $6(0.075)$ & $5(0.833)$ & $2(0.333)$ & $5(0.833)$ \\
\hline Staphylococcus lentus & $5(0.063)$ & $2(0.400)$ & $2(0.400)$ & $1(0.200)$ \\
\hline Staphylcoccus haemolyticus & $4(0.050)$ & $1(0.250)$ & $0(0.000)$ & $2(0.500)$ \\
\hline Staphylococcus vitulinus & $4(0.050)$ & $4(1.000)$ & $4(1.000)$ & 3() $.750)$ \\
\hline Staphylococcus kloosii & $3(0.038)$ & $2(0.667)$ & $2(0.667)$ & $2(0.667)$ \\
\hline Staphylococcus pettenkoferi & $3(0.038)$ & $3(1.000)$ & $0(0.000)$ & $3(1.000)$ \\
\hline Staphylococcus cohnii subsp. urealyticum & $2(0.025)$ & $1(0.500)$ & $1(0.500)$ & $1(0.500)$ \\
\hline Staphylococcus lugdunensis & $2(0.025)$ & $2(1.000)$ & $0(0.000)$ & $1(0.500)$ \\
\hline Staphylococcus warneri & $2(0.025)$ & $2(1.000)$ & $1(0.500)$ & $2(1.000)$ \\
\hline Staphylococcus xylosus & $2(0.025)$ & $1(0.500)$ & $1(0.500)$ & $2(1.000)$ \\
\hline Staphylococcus auricularis & $1(0.012)$ & $0(0.000)$ & $0(0.000)$ & $1(1.000)$ \\
\hline Staphylococcus chromogenes & $1(0.012)$ & $0(0.000)$ & $0(0.000)$ & $1(1.000)$ \\
\hline Staphylococcus cohnii subsp. cohnii & $1(0.012)$ & $1(1.000)$ & $1(1.000)$ & $0(0.000)$ \\
\hline Staphylococcus epidermidis & $1(0.012)$ & $1(1.000)$ & $0(0.000)$ & $1(1.000)$ \\
\hline Staphylococcus hominis & $1(0.012)$ & $0(0.000)$ & $0(0.000)$ & $1(1.000)$ \\
\hline Staphylococcus intermedius & $1(0.012)$ & $0(0.000)$ & $0(0.000)$ & $1(1.000)$ \\
\hline Total & 80 & $40(0.500)$ & $22(0.275)$ & $58(0.725)$ \\
\hline
\end{tabular}

${ }^{1}$ in brackets: proportion of isolates of the species among all isolates; ${ }^{2}$ resistant to any (at least one) antibiotic; ${ }^{3}$ in brackets: proportion of resistant, multi-resistant, or biofilm-forming isolates among the isolates of the respective species. 
Resistant (to at least one (any) antibiotic) or multi-resistant staphylococci were obtained from 36 (30.3\%, 95\% CI: 22.7-39.0\%) or 19 (16.0\%, 95\% CI: 10.5-23.6\%) herds, respectively. There was no difference in the proportion of farms in which resistant staphylococcal isolates were recovered according to their geographic part of the country, where they were located $(p=0.39)$ (Table 2).

Table 2. Recovery of resistant staphylococcal isolates from bulk-tank milk of 119 goat herds in Greece, according to the part of the country from which the herds originated.

\begin{tabular}{ccc}
\hline $\begin{array}{c}\text { Location of Herds (Part } \\
\text { of the Country) }\end{array}$ & Herds $(\boldsymbol{n})$ & $\begin{array}{c}\text { Herds in Which Resistant Staphylococcal } \\
\text { Isolates Were Recovered }(\boldsymbol{n})^{\mathbf{1}}\end{array}$ \\
\hline $\begin{array}{c}\text { Central part } \\
\text { Islands }\end{array}$ & 36 & $13(0.361)$ \\
Northern part & 16 & $2(0.125)$ \\
Southern part & 36 & $11(0.306)$ \\
\hline
\end{tabular}

${ }^{1}$ in brackets: proportion of herds in which resistant staphylococcal isolates were recovered among all herds.

Of the 80 staphylococcal isolates, 40 (50.0\%, 95\% CI: 39.3-60.7\%) (5 S. aureus and 35 coagulase-negative isolates, $p=0.005$ for comparison between $S$. aureus and coagulasenegative staphylococci; $p=0.026$ for comparison between the various coagulase-negative species) were resistant to antibiotics. Further, 22 isolates (27.5\%, 95\% CI: $18.9-38.1 \%$ ) (all coagulase-negative isolates, $p=0.001$ for comparison between $S$. aureus and coagulasenegative staphylococci; $p=0.030$ for comparison between the various coagulase-negative species) were multi-resistant. Details are presented in Table 1.

At isolate level, resistance was found more frequently against penicillin and ampicillin (33 isolates, $41.3 \%$ of all isolates), fosfomycin (22 isolates, $27.5 \%$ of all isolates), clindamycin (19 isolates, $23.8 \%$ of all isolates), erythromycin (16 isolates, $20.0 \%$ of all isolates), tetracycline (12 isolates, $15.0 \%$ of all isolates) and oxacillin (6 isolates, $7.5 \%$ of all isolates) (Table S1).

At herd level, staphylococci resistant to penicillin and ampicillin were isolated from 30 (25.2\%, 95\% CI: $18.3-33.7 \%$ ) herds, to fosfomycin from 20 (16.8\%, 95\% CI: $11.2-24.5 \%)$, to clindamycin from 17 (14.3\%, 95\% CI: 9.1-21.7\%), to erythromycin from $14(11.8 \%, 95 \%$ CI: 7.1-18.8\%), to tetracycline from $9(7.6 \%, 95 \%$ CI: $4.0-13.8 \%)$, and to oxacillin from $6(5.0 \%$, 95\% CI: $2.3-10.6 \%$ ) herds.

Among the staphylococcal species, $S$. aureus was found to be resistant more frequently to penicillin (3/21 isolates), $S$. equorum was found to be resistant more frequently to ampicillin, erythromycin, penicillin, fosfomycin, and clindamycin (8/11,8/11, 8/11, 7/11, and $6 / 11$ isolates, respectively), and $S$. capitis to ampicillin, fosfomycin and penicillin (5/6 isolates for each antibiotic) (Table S1).

\subsection{Biofilm Formation}

Of the 80 isolates, 58 (72.5\%, 95\% CI: 61.9-81.1\%) were found to be biofilm forming (Table 1). No association was seen between biofilm formation and resistance to antibiotics. Of the 40 resistant isolates, 28 (70.0\%, 95\% CI: 54.6-81.9\%) (4 S. aureus and 24 coagulasenegative isolates) were biofilm forming $(p=0.62)$. Of the 22 multi-resistant isolates, 14 (63.6\%, 95\% CI: 43.0-80.3\%) (all coagulase-negative isolates) were biofilm forming ( $p=0.27)$. Further, no association was found with specific resistance to the antibiotics evaluated ( $p>0.14$ for all comparisons) (Table S2), as well as no association was found for specific staphylococcal species ( $p>0.12$ for all comparisons).

\subsection{Associations with Milk Quality}

Increased total bacterial counts (i.e., $>1500 \times 10^{3} \mathrm{cfu} \mathrm{mL}^{-1}$, which is the threshold set in the European Union for milk to undergo thermal processing [10]) were seen more commonly among herds from bulk-tank milk of which resistant staphylococcal isolates were recovered: $12 / 36(33.3 \%)$ herds versus $17 / 83(20.5 \%)$ herds without isolation of 
resistant staphylococci $(p=0.010)$. No other association of milk quality with the isolation of resistant staphylococci was found (Table S3).

2.4. Variables Associated with Isolation of Resistant or Multi-Resistant Staphylococcal Isolates from Bulk-Tank Milk

2.4.1. Isolation of Oxacillin-Resistant Staphylococcal Isolates

During the univariable analysis, a significant association with isolation of oxacillinresistant staphylococcal isolates from bulk-tank milk was evident for 2 of the 25 variables evaluated (Table S4). These were the following: education of the farmer and presence of working staff in the herd.

Among the variables included in the multivariable analysis (Tables S4 and S5), only the following emerged as a significant factor: presence of working staff in the herd (Figure 1) $(p=0.005)$ (Table 3).

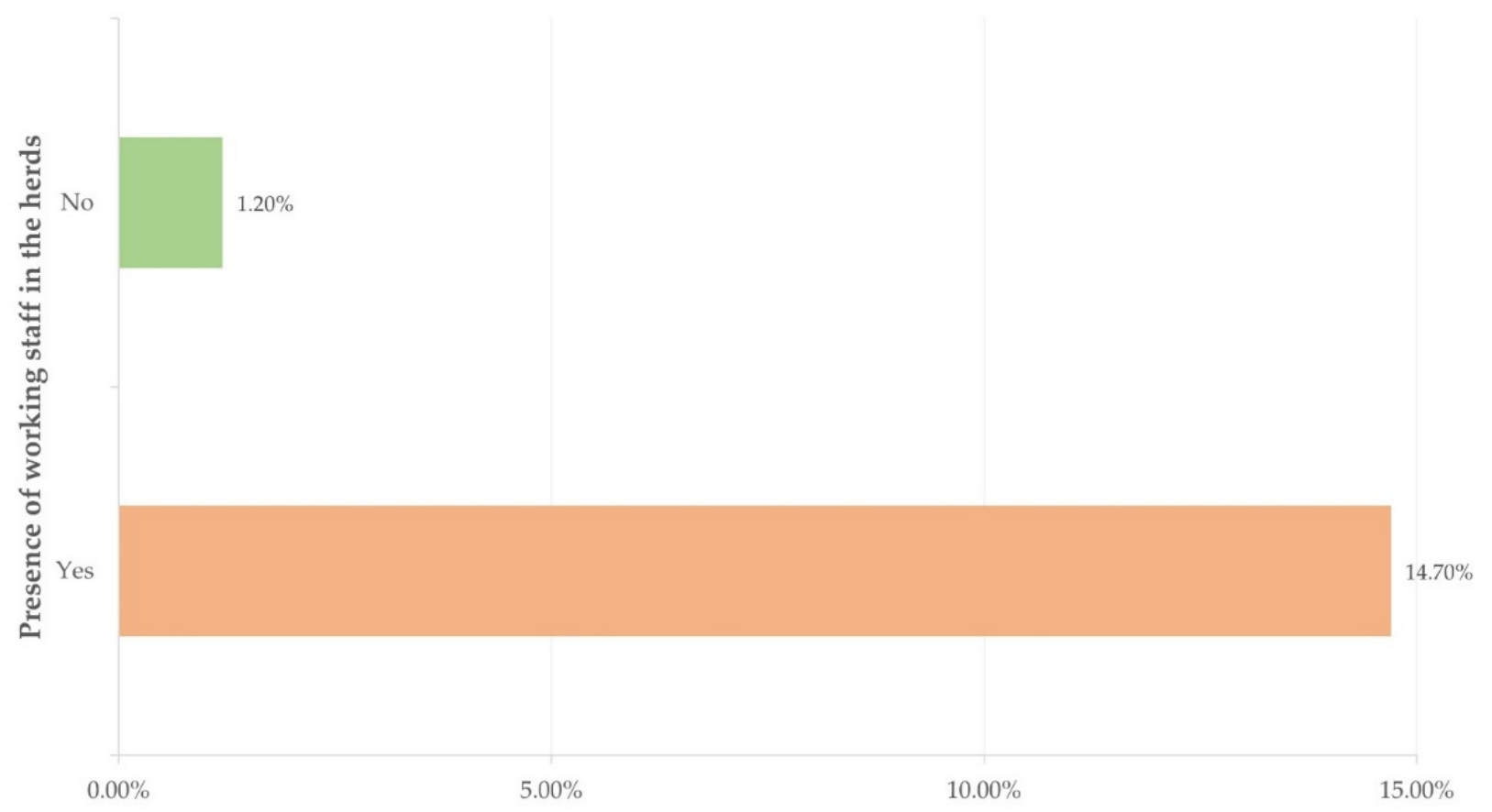

Proportion of herds, from the bulk-tank milk of which oxacillin-resistant staphylococcal isolates were recovered

Figure 1. The proportion of herds from which oxacillin-resistant staphylococcal isolates were recovered, in terms of the presence of working staff in these herds.

Table 3. Results of multivariable analysis for isolation of oxacillin-resistant staphylococcal isolates from bulk-tank milk of 119 goat herds in Greece.

\begin{tabular}{ccc}
\hline Variable $(\boldsymbol{n = 1 )}$ & $\begin{array}{c}\text { Odds Ratio }^{\mathbf{1}} \\
\mathbf{( 9 5 \%}^{\text {Confidence Intervals) }}\end{array}$ & $\boldsymbol{p}$ \\
\hline Presence of working staff in the herd & & 0.005 \\
\hline Yes $(n=34)$ & $14.483(1.624-129.171)$ \\
No $(n=85)$ & reference & 0.017 \\
\hline
\end{tabular}

${ }_{1}$ odds ratio calculated against the lowest prevalence associations of variables.

\subsubsection{Isolation of Staphylococcal Isolates Resistant to at Least One Antibiotic}

During the univariable analysis, a significant association with isolation of resistant staphylococcal isolates from bulk-tank milk was evident for 6 of the 25 variables evaluated (Table S6). These were the following: management system applied in the herd, annual frequency of systemic disinfections in the farm, routine administration of antimicrobials in 
newborns, administration of 'dry-ewe' treatment at the end of the lactation period, farmer by profession, and presence of working staff in the herd.

Among the variables included in the multivariable analysis (Tables S5 and S6), the following two emerged as significant factors: (a) farmer by profession $(p=0.001)$ and (b) annual frequency of systemic disinfections in the farm $(p=0.018)$ (Figure 2) (Table 4).

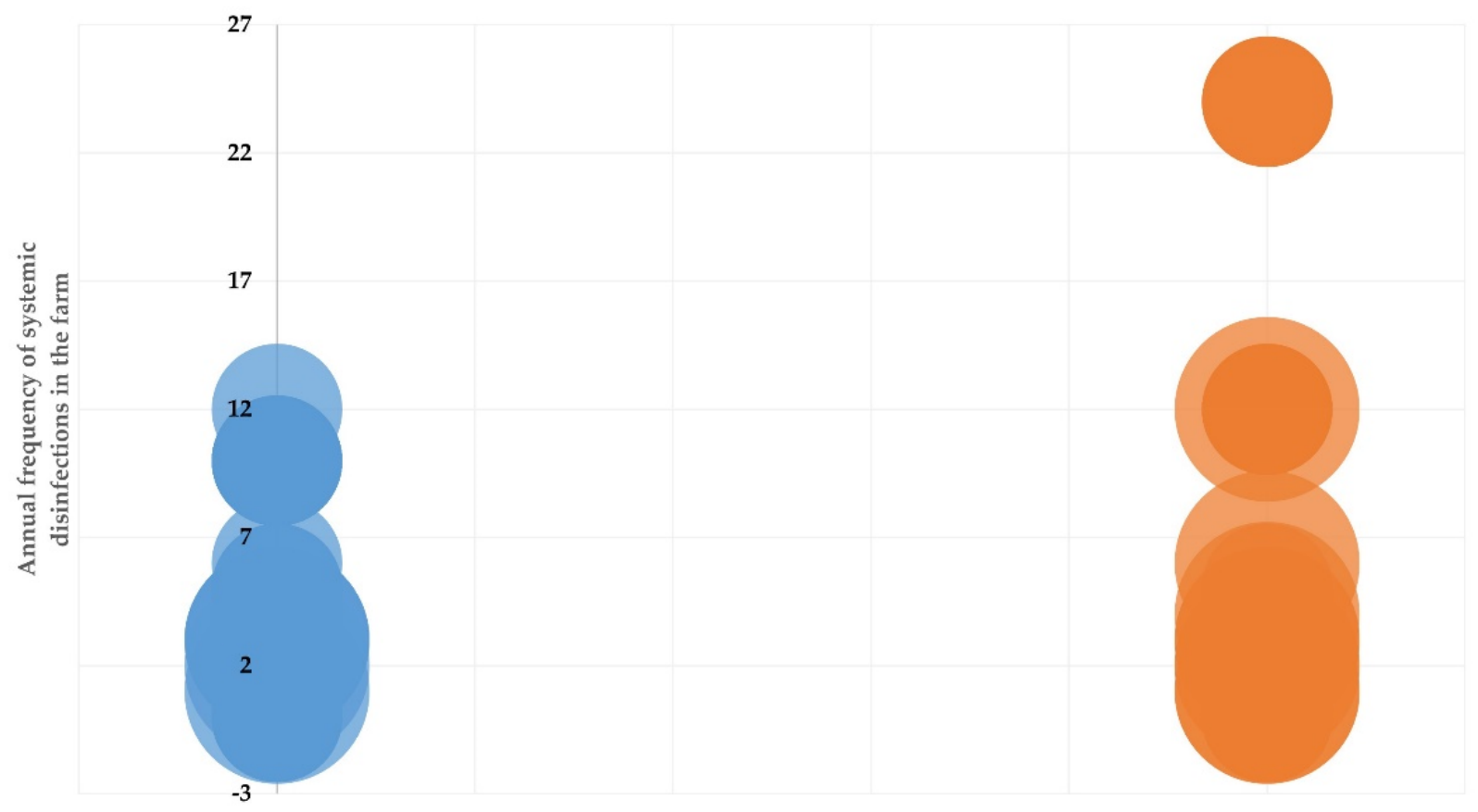

Figure 2. Frequency (shown by the circle diameter) of herds from which resistant staphylococcal isolates were (orange circles, $n=36$ ) or were not (blue circles, $n=83$ ) recovered from bulk-tank milk, in relation to the number of systemic disinfections performed annually in the herd (vertical axis; $0-1$ occasions, $n=33,2-10$ occasions, $n=76,>10$ occasions, $n=10$ ) and the professional capacity of the farmer (solid pattern of circles: full-time farmers, $n=105$; motif pattern of circles: part-time farmers, $n=14$ ).

Table 4. Results of multivariable analysis for isolation of resistant staphylococcal isolates from bulk-tank milk of 119 goat herds in Greece.

\begin{tabular}{ccc}
\hline Variable $(\boldsymbol{n = 2 )}$ & $\begin{array}{c}\text { Odds Ratios }^{\mathbf{1}} \\
\mathbf{9 5 \%} \text { Confidence Intervals) }\end{array}$ & $p$ \\
\hline Farmer by profession & reference & 0.001 \\
\hline $\begin{array}{c}\text { Full-time }(n=105) \\
\text { Part-time }(n=14)\end{array}$ & $5.200(1.602-16.882)$ & - \\
\hline $\begin{array}{c}\text { Annual frequency of systemic } \\
\text { disinfectionsin the farm }\end{array}$ & reference & 0.006 \\
\hline 0-1 occasion $(n=33)$ & $1.327(0.499-3.529)$ & 0.018 \\
$2-10$ occasions $(n=76)$ & $33.429(3.601-310.331)$ & - \\
$>10$ occasions $(n=10)$ & & 0.57 \\
\hline
\end{tabular}

${ }_{1}$ odds ratio calculated against the lowest prevalence associations of variables.

\subsubsection{Isolation of Multi-Resistant Staphylococcal Isolates}

During the univariable analysis, a significant association with isolation of multiresistant staphylococcal isolates from bulk-tank milk was evident for 3 of the 12 variables evaluated (Table S7). These were the following: annual frequency of systemic disinfections in the farm, farmer by profession, and presence of working staff in the herd.

Additionally, the same three emerged as significant among the variables included in the multivariable analysis (Tables S5 and S7): (a) annual frequency of systemic disinfections 
in the farm $(p=0.002)$, (b) presence of working staff in the herd $(p=0.016)$, and (c) farmer by profession $(p=0.022)$ (Table 5$)$.

Table 5. Results of multivariable analysis for isolation of multi-resistant staphylococcal isolates from bulk-tank milk of 119 goat herds in Greece.

\begin{tabular}{ccc}
\hline Variable $(\boldsymbol{n}=\mathbf{3})$ & $\begin{array}{c}\text { Odds Ratio }^{\mathbf{1}} \\
\text { (95\% Confidence Intervals) }\end{array}$ & $\boldsymbol{p}$ \\
\hline $\begin{array}{c}\text { Annual frequency of systemic } \\
\text { disinfectionsin the farm }\end{array}$ & reference & 0.002 \\
\hline $0-1$ occasion $(n=33)$ & $1.343(0.339-5.317)$ & - \\
$2-10$ occasions $(n=76)$ & $23.333(3.859-141.077)$ & 0.67 \\
$>10$ occasions $(n=10)$ & & 0.0006 \\
\hline Presence of working staff in the herd & $3.519(1.281-9.668)$ & 0.016 \\
\hline Yes $(n=34)$ & reference & 0.015 \\
No $(n=85)$ & reference & - \\
\hline Farmer by profession & $3.611(1.056-12.349)$ & - \\
\hline Yes $(n=105)$ & & 0.022 \\
No $(n=14)$ & &
\end{tabular}

${ }_{1}^{1}$ odds ratio calculated against the lowest prevalence associations of variables.

\section{Discussion}

The European Food Safety Authority has published a scientific opinion [11] that pointed out the public health significance of antibiotic resistance of bacteria isolated from raw milk. Hence, it is relevant to study the patterns of resistance in goat farms. Moreover, the evaluation and identification of predictors related to management could allow the implementation of procedures that help to limit the presence of antibiotic resistance in the farms.

This study included goat farms from all parts of Greece. Thus, conditions prevailing throughout the country were taken into account, and factors of regional importance weighed less. In order to minimise possible bias, the study also used consistent methodologies and ensured that specific tasks were always performed by the same investigators.

\subsection{Presence of Antibiotic Resistance in Staphylococcal Isolates}

In previous studies of caprine mastitis, S. caprae, S. chromogenes, S. epidermidis, S. simulans, S. warneri, and S. xylosus predominated as causal agents of the infection $[12,13]$. This indicates that many of the recovered isolates in the current study possibly originated from sources outside the animals. Apart from the milk of the goats (i.e., as agents of mastitis), the staphylococci could have originated from the skin udder and teat or from the equipment for milk handling and storage (e.g., teat cups, pipelines, milk tank) [14]. Further, in herds in which hand milking is applied, the staphylococci might have also originated from the hands of the milkers [15].

The extent of antibiotic resistance was, in general, similar to that presented in other relevant reports from the para-Mediterranean region where dairy goats are kept and milk is produced for human consumption. The results of this study showed low-level resistance among S. aureus isolates but a significantly greater problem among the coagulasenegative isolates. $S$. aureus is a significant causal agent of clinical mastitis in goats; it can be diagnosed easily and then followed by the initiation of appropriate treatment. In contrast, coagulase-negative isolates cause subclinical mastitis, an infection of lesser severity, which is difficult to diagnose and thus is treated infrequently. These organisms are also present in the environment or are part of a carrier state [16] in the animals; therefore, there are more opportunities for exposure to factors that lead to the development of resistance. These results are in line with those of a recent study that we performed on the antibiotic resistance patterns of ovine mastitis pathogens, where S. aureus isolates showed significantly less 
frequent resistance than the coagulase-negative isolates [17]. It is also possible that some of the coagulase-negative isolates originated from people (e.g., farm personnel), as some species (e.g., S. hominis or S. haemolyticus) are confirmed human pathogens. Moreover, the detection of resistance to fosfomycin, which is not licenced for veterinary use, further supports the suggestion that some of the recovered isolates likely were of human origin.

Limited associations were found between the recovery of resistant staphylococcal isolates from the milk and its quality. The increased total bacterial counts may also reflect a difficulty in treating cases of mastitis, due to the presence of resistant isolates [18] or also, possibly, the development of resistance by relevant bacteria in the farm. As total bacterial counts over the threshold of $1500 \times 10^{3} \mathrm{cfu} \mathrm{mL}^{-1}$ could result in penalties in the milk price paid to farmers, the presence of resistant isolates would have tangible adverse consequences to farmers.

\subsection{Predictors for Antibiotic-Resistant Staphylococcal Isolates}

Three factors were found to be associated with the presence of resistance in the staphylococcal isolates recovered during the study. This suggests that there are many aspects of farm systems that can influence the development of antibiotic resistance.

Professional farmers have obviously appreciated the importance of preventing the development of antibiotic resistance in their herds. This had been repeatedly underlined in many relevant campaigns in Greece, staged by various public and private organisations within their areas of responsibility [19]. One such campaign was initiated by the Hellenic Veterinary Association [20] and involved the production of leaflets for farmers and the distribution to professionals to inform them about the significance of resistant bacterial isolates for the animals (e.g., increased animal morbidity and adverse financial effects) and the potential transmission to humans. Additionally, veterinarians would discuss with farmers and highlight the importance of preventing antibiotic resistance. We can thus postulate that part-time farmers were not fully aware of the importance of the problem and were following practices and procedures that promoted the development of resistance.

The increased number of disinfections performed in the herds was also identified as a significant predictor for the recovery of resistant isolates. The long-standing use of disinfectants has been found to lead to the development of resistance to these by staphylococcal isolates, especially given that many isolates bear genes specific for the development of resistance to these biocides (e.g., qac, which encodes for resistance to quaternary ammonium compounds [21]). The use of disinfectants in goat farms is related to cleaning and to the maintenance of biosecurity, aiming to protect animals and people against harmful biological agents. In piggeries also, the development of methicillin-resistance of staphylococcal isolates has been associated with increased use of disinfectants [22]. In dairy farms, this association is of particular concern, due to the necessity for increased and frequent use of disinfectants, as part of the routine for parlour cleaning post-milking. This also increases the chances for resistant bacterial isolates to enter into the chain of milk production, as was seen in this study. Cross-resistance of disinfectants with antibiotics has been shown in various bacteria $[23,24]$, and wide use of benzalkonium-type disinfectants can promote antibiotic resistance due to co-selection. Further, according to some studies, there is a linkage between antibiotic and disinfectant resistance, which is either genetic (i.e., co-localisation of responsible genes in plasmid elements [25]) or functional [26], and the strains carrying both traits appear to have a strong selective advantage, due to their positive selection from the intense selective pressures, leading to the prevalence of multidrug resistance species. Various studies have revealed the genes and genetic networks responsible for the development of resistance mechanisms; their dissemination across strains and species is enhanced by specific mechanisms, while horizontal gene transfer figures are at the top of the list of the exchange of genetic elements. Resistance to antibiotics and disinfectants has been found to be highly associated in various bacterial species (e.g., resistance genes qacF, qacE $\Delta 1$, tet, sul [27]), underlying the possibility that common mechanisms are governing the resistance mechanisms to multiple substances. Moreover, staphylococcal isolates can 
harbour multiple plasmids responsible for resistance to antibiotics, heavy metals, antiseptics, and disinfectants [28-30], which can explain the strong association between increased frequency of systemic disinfections and antibiotic resistance. Some of these genes can also encode for resistance to antibiotics, and it is possible that the use of disinfectants could lead to the elimination of susceptible isolates, thus contributing to the increased prevalence of multidrug-resistant isolates. These pose serious threats to both human and animal populations, leading to the development of alternative approaches to control bacterial growth [31], which will enhance the levels of biosecurity and the avoidance of threats for public health.

The presence of working staff in a farm was seen more often in herds with intensive management ( $78 \%$ of herds with intensive management in this study), where practices found to be associated with recovery of resistant isolates are often performed; working staff would be necessary for such time-consuming tasks, e.g., administration of antibiotics to newborns, frequent disinfections etc., etc. In their majority (in 32 of 36 herds, 89\%; Lianou unpublished data) the working staff were of non-Greek ethnicity and possibly did not speak the local language well; therefore, one may postulate that they might not have fully assimilated the campaigns for preventing antibiotic resistance, thus following practices that might have contributed to that. Moreover, a study in the United States indicated that farmworkers could be healthy carriers of antibiotic-resistant bacterial strains [32]. Hence, they could have disseminated these within their farm or even to other farms if they changed their workplace.

\section{Materials and Methods}

\subsection{Goat Herds and Sampling}

A cross-sectional study involving 119 herds was performed from April 2019 to July 2020 and covered all the 13 administrative regions of Greece (Figure 3). Herds were included in the study on a convenience basis (willingness of goatherds to accept a visit by university personnel for interview and sample collection), as detailed before [5]. The principal investigators (D.T.L. and G.C.F.), accompanied by other investigators, visited all the herds for sample collection.

Initially, the management practices applied in the herds were recorded during an interview of the goatherd by means of a detailed questionnaire [33]. Bulk-tank milk samples were taken aseptically from each herd for somatic cell counting and milk composition evaluation and for bacteriological examinations. Samples were packed at 0.0 to $4.0^{\circ} \mathrm{C}$ and transported for laboratory examinations [5]. 


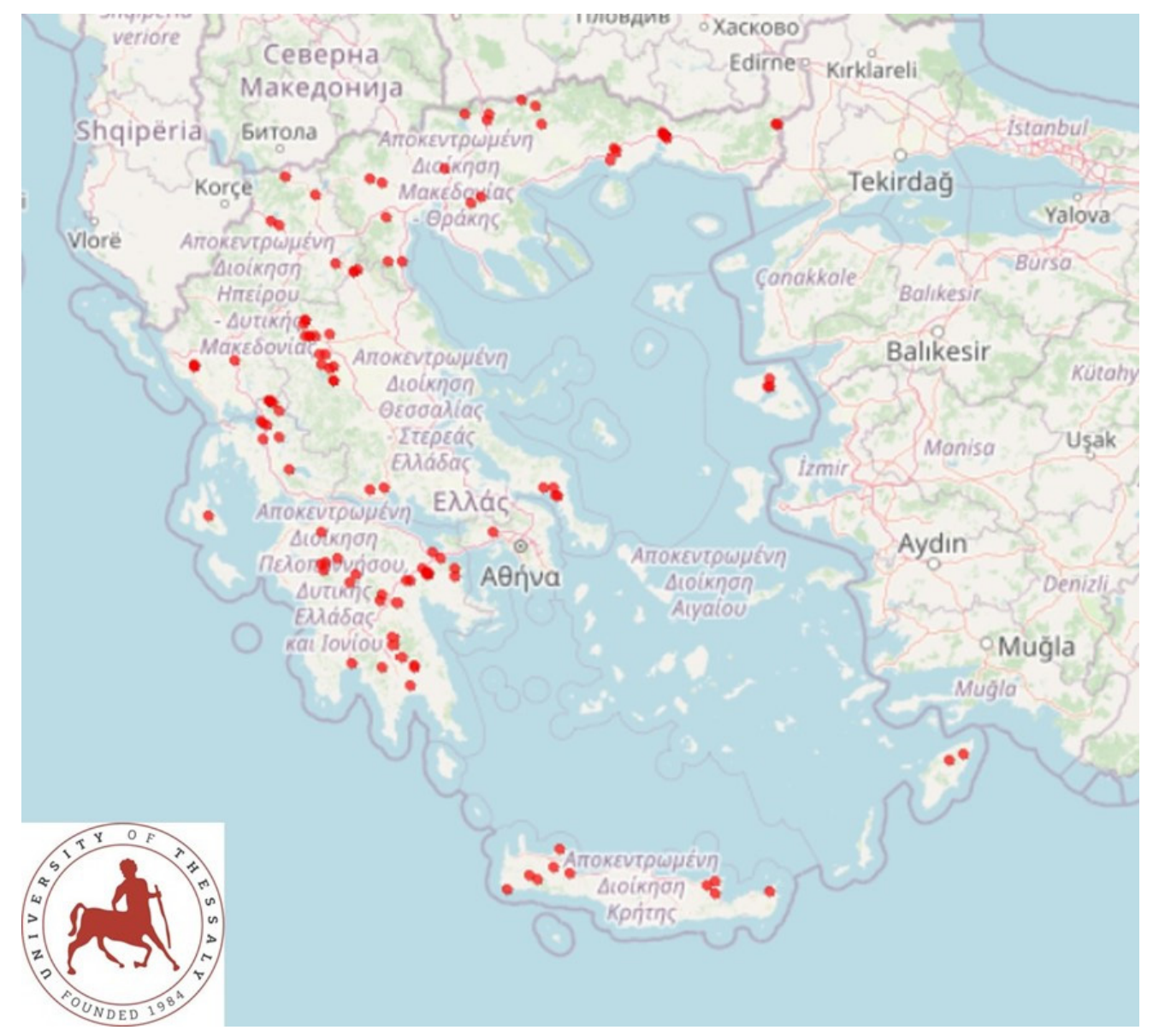

Figure 3. Location of 119 goat herds around Greece, which were visited for bulk-tank milk sampling.

\subsection{Laboratory Examinations}

Two milk samples from each bulk tank were used for somatic cell counts (SCC) and milk composition measurement; the other two were used for the bacteriological examinations. Two sub-samples were created and processed from each of the four samples so that each separate test was performed four times (each one in different sub-samples).

Somatic cell counting and milk content measurement were performed within $4 \mathrm{~h}$ of collection, whilst bacteriological examinations started within $24 \mathrm{~h}$ after collection of samples [Lianou et al. 2021]. Bacteriological examinations from each of the four relevant subsamples included total bacterial counts (TBC), performed by employing the standardised procedures described by Laird et al. [34] and culturing on Staphylococcus selective medium (Mannitol salt agar; BioPrepare Microbiology, Athens, Greece) for aerobic incubation at $37{ }^{\circ} \mathrm{C}$ for $48 \mathrm{~h}$; if there was no growth, media were reincubated for a further $24 \mathrm{~h}$. After completion of sample aliquot withdrawal for microbiological examination, the temperature of the respective samples was measured and was never found to exceed $3.8^{\circ} \mathrm{C}$.

Bacterial isolation and initial identification by means of Gram staining and evaluation of catalase production were performed using standard methods [35,36]. Definite identification of the staphylococcal isolates to species level was performed by using matrix-assisted laser desorption/ionisation time-of-flight mass spectrometry (VITEK MS; BioMerieux, Marcy-l'-Étoile, France).

Then, in vitro biofilm formation by the staphylococcal isolates was evaluated. This was performed by using the combination of (a) the culture appearance on Congo Red agar plates and (b) the results of a microplate adhesion test. The procedures were detailed by Vasileiou et al. [37] for staphylococcal isolates recovered from milk. 
Finally, the susceptibility testing to 20 antibiotics (amikacin, ampicillin, ceftaroline, ciprofloxacin, clindamycin, erythromycin, fosfomycin, fusidic acid, gentamicin, linezolid, moxifloxacin, mupirocin, mupirocin high level, oxacillin, penicillin $G$, rifampin, teicoplanin, tetracycline, tobramycin, trimethoprim-sulfamethoxazole) was performed by means of the automated system BD Phoenix ${ }^{\text {TM }}$ M50 (BD Diagnostic Systems, Sparks, MD, USA). The interpretation of the results was based on the criteria of the European Committee on Antimicrobial Susceptibility Testing (EUCAST) (http:/ / www.eucast.org (accessed on 17 September 2021)).

\subsection{Data Management and Analysis}

\subsubsection{Data Management}

The presence of staphylococci in bulk-tank milk was defined by the isolation of $\geq 3$ staphylococcal colonies on at least one agar plate of the four that were cultured with a sub-sample from each bulk-tank milk from a herd.

Biofilm formation by the staphylococcal isolates was indicated by a combination of the results of the two methods (culture appearance on Congo Red agar and microplate adhesion) [37] and staphylococcal strains were then characterised as biofilm-forming or non-biofilm-forming.

Based on the results of susceptibility/resistance testing, isolates were classified as susceptible, susceptible increased exposure, or resistant to each antibiotic according to the EUCAST criteria. As no 'susceptible increased exposure' isolates were found, this possible result was omitted from the analyses. Multidrug-resistant isolates were those found resistant to at least three different classes of antibiotics [38].

During cell counting, total bacterial counting, and milk content measurement for each bulk-tank milk sample, the results of the two sub-samples from each sample were averaged, and then the two means were again averaged for the final result regarding each bulk-tank milk.

SCCs were transformed to somatic cell scores (SCS) $[39,40]$ by using the following formula: $\mathrm{SCS}=\log _{2}(\mathrm{SCC} / 100)+3$, and TBCs were transformed to $\log _{10}$; for both parameters, the transformed data were used in the analyses. For the presentation of results, the transformed findings were back-transformed as follows: $100 \times 2^{(\mathrm{SCS}-3)}$ for SCC and $10^{\log }$ for TBC data.

\subsubsection{Statistical Analysis}

Data were entered into Microsoft Excel and analysed using SPSS v. 21 (IBM Analytics, Armonk, NY, USA). Basic descriptive analysis was performed. Exact binomial confidence intervals $(\mathrm{CI})$ were obtained.

The country was divided into four parts: central part, islands, northern part, and southern part, and herds were allocated to the appropriate one according to their geographical location. Pearson's chi-squared test was employed to compare between the four parts of the country, the proportions of herds in each one, in which staphylococcal isolates were recovered.

In total, 25 variables were evaluated for potential association with the recovery of staphylococcal isolates resistant to antibiotics from bulk-tank milk of these herds (Appendix A); these were either taken directly from the answers of the interview performed at the start of the visit or calculated based on these answers. For each of these variables, categories were created according to the answers of the farmers.

The outcomes of 'isolation of oxacillin-resistant staphylococcal isolates from bulk-tank milk' and 'isolation of resistant staphylococcal isolates from bulk-tank milk' (i.e., isolates resistant to any (at least one) antibiotic) were considered. Exact binomial CIs were obtained. Initially, the importance of predictors was assessed by using cross-tabulation with Pearson's chi-squared test and with simple logistic regression. Subsequently, multivariable models were created, initially offering to the model all variables, which achieved a significance of $p<0.2$ in the univariable analysis. Variables were removed from the initial model by 
backward elimination. The $p$ value of removal of a variable was assessed by the likelihood ratio test, and for those with a $p$ value of $>0.2$, the variable with the largest probability was removed. This process was repeated until no variable could be removed with a $p$ value of $>0.2$. The variables required for the final multivariable models are shown in Table S5.

Subsequently, the outcome of 'isolation of multi-resistant staphylococcal isolates from bulk-tank milk' was considered. Only the variables that achieved $p<0.2$ in the analysis for isolation of resistant staphylococci were evaluated, and the same procedures as above (i.e., univariable and multivariable analyses) were performed. The variables required for the final multivariable model are shown in Table S5.

Finally, the potential association of isolation of a resistant staphylococcal isolate with SCC, TBC, and composition of bulk-tank milk was assessed by using a one-way analysis of variance.

In all analyses, statistical significance was defined at $p \leq 0.05$.

\section{Conclusions}

The recovery of resistant staphylococci in bulk-tank milk in goat farms, which is intended for human consumption, raises concerns within the 'one health' concept. Potentially, the genetic material of these resistant staphylococci, which is not destroyed during the thermal processing of milk, might possibly be transferred to humans [41,42]. These genes could be incorporated into other bacteria, which constitute a part of the normal flora of humans. Thus, further dissemination of resistance genes can occur. Resistant staphylococcal isolates in raw milk from goats act as 'containers' of resistance genes and the dairy products as the means for their dissemination. This indicates the need for limiting the staphylococcal presence in the milk and for preventing resistance development in dairy goat herds, finally reducing the relevant public health concerns.

The current findings focused on identifying variables and factors in goat herds that can be related to the presence of resistant isolates in raw milk. These findings should act as a guide to allow the application of good practices, thus contributing to preventing the development of resistance and supporting the 'one health' concept.

As a future prospect, modern genetics and genomics techniques, such as multi-locus sequence typing (MLST) or whole-genome sequencing (WGS), can be applied, in order to study the origin of such resistant isolates (e.g., from people or other animals in the farms). Thus, further measures can be applied to minimise the risk of cross-species transmission events and to reduce the prevalence of staphylococcal species in milk and dairy products.

Supplementary Materials: The following are available online at https:/ / www.mdpi.com/article/10 .3390 /antibiotics10101225/s1, Table S1: Frequency of susceptibility/resistance to individual antibiotics of staphylococcal isolates recovered from bulk-tank milk of 119 goat herds in Greece, Table S2: Details of associations of antibiotic resistance with biofilm formation by staphylococcal isolates from bulk-tank milk of 119 goat herds in Greece, Table S3: Details of associations of milk quality with isolation of resistant or multi-resistant staphylococcal isolates from bulk-tank milk of 119 goat herds in Greece, Table S4: Results of univariable analysis for association with isolation of oxacillin-resistant staphylococcal isolates from bulk-tank milk of 119 goat herds in Greece, Table S5: Details of multivariable models employed for the evaluation of the isolation of resistant staphylococcal isolates from bulk-tank milk of 119 goat herds in Greece, Table S6: Results of univariable analysis for association with isolation of staphylococcal isolates resistant to at least one antibiotic from bulk-tank milk of 119 goat herds in Greece, Table S7: Results of univariable analysis for association with isolation of multi-resistant staphylococcal isolates from bulk-tank milk of 119 goat herds in Greece.

Author Contributions: Conceptualisation, D.T.L. and G.C.F.; methodology, D.T.L., E.P., P.J.C., C.V. and G.C.F.; formal analysis, D.T.L., P.J.C. and D.A.G.; investigation, D.T.L., C.K.M., K.T., A.S., A.I.K., N.G.C.V., E.I.K., C.V. and G.C.F.; resources, D.T.L. and G.C.F.; data curation, D.T.L.; writing-original draft preparation, D.T.L. and G.C.F.; writing-review and editing, E.P., T.G., V.S.M., M.C. and G.C.F.; visualisation, D.T.L.; supervision, E.P., V.S.M., M.C. and G.C.F.; project administration, E.P. and G.C.F.; funding acquisition, E.P. and G.C.F. All authors have read and agreed to the published version of the manuscript. 
Funding: This research received no external funding.

Institutional Review Board Statement: The protocols of the study were approved by the academic board of the Veterinary Faculty of the University of Thessaly, Meeting 34/03.04.19.

Informed Consent Statement: Not applicable.

Data Availability Statement: Most data presented in this study are in the Supplementary Materials. The remaining data are available on request from the corresponding author. The data are not publicly available as they form part of the PhD thesis of the first author, which has not yet been examined, approved, and uploaded in the official depository of $\mathrm{PhD}$ theses from Greek Universities.

Acknowledgments: The help received by the veterinarians, who selected the herds and arranged the visits to these for sample collection, is gratefully acknowledged.

Conflicts of Interest: The authors declare no conflict of interest.

\section{Appendix A}

Table A1. Variables $(n=25)$ evaluated for potential association with the presence of antibiotic resistance in staphylococci isolated from bulk-tank milk of 119 goat herds in Greece.

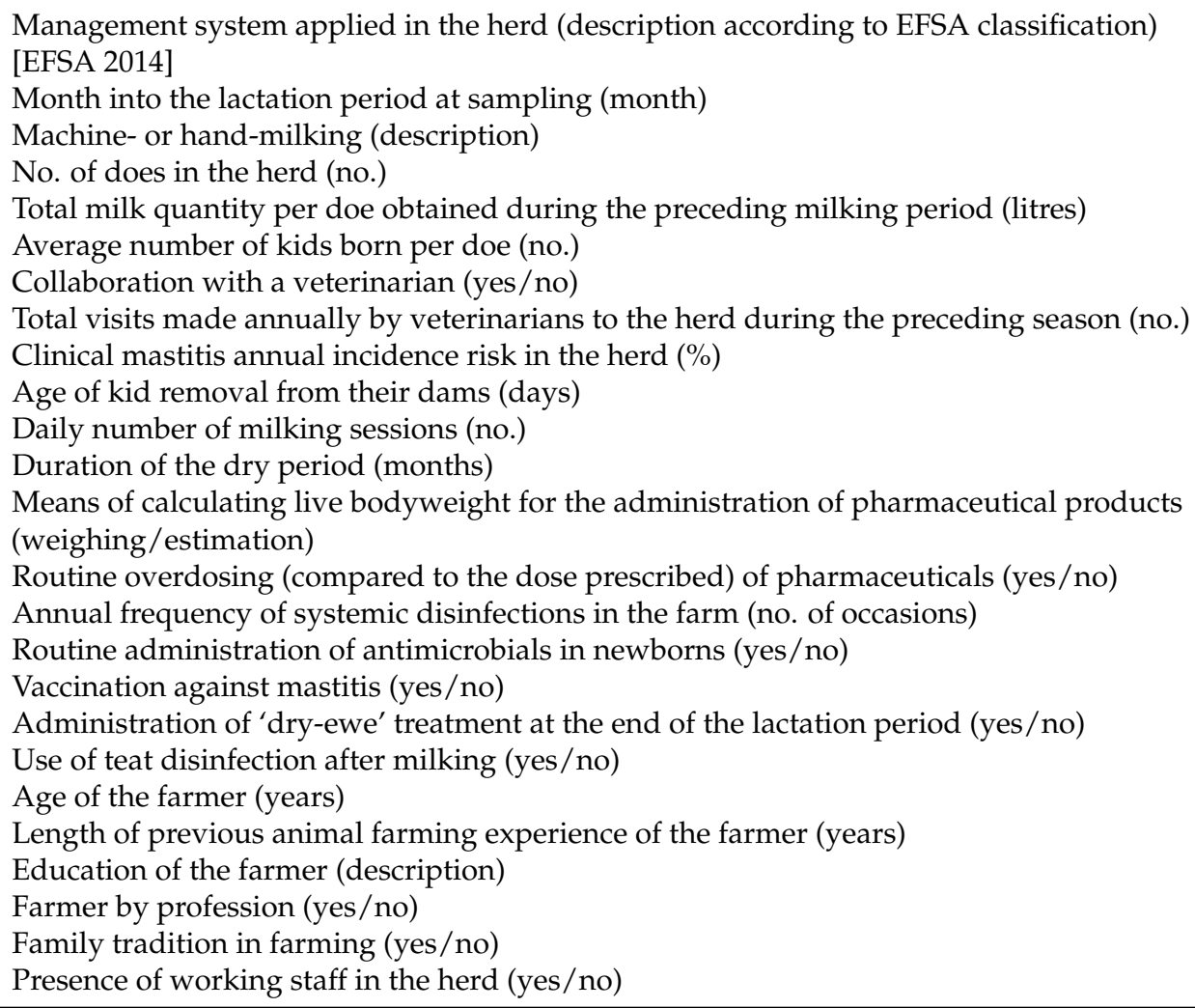

\section{References}

1. Hellenic Agricultural Organisation-Demeter (2020). Deliveries of Ovine and Caprine Milk by Region and Regional Authority and Average Milk Price-Calendar Year 2019. Cumulative Data Updated. Available online: https://www.elgo.gr/images/ ELOGAK_files/Statistics /2020/AIGO_\%CE\%A0\%CE $\%$ B1\%CF $\% 81 \% C E \% B 1 \% C E \% B 4 \% C F \% 8 C \% C F \% 83 \% C E \% B 5 \% C E \% B 9$ $\% \mathrm{CF} \% 82$ \%CE\%A0\%CF\%81\%CF\%8C\%CE\%B2\%CE\%B5\%CE\%B9\%CE\%BF\%CF\%85_\%CE\%BA\%CE\%B1\%CE\%B9_\%CE\%93 $\% \mathrm{CE} \% \mathrm{AF} \% \mathrm{CE} \% \mathrm{~B} 4 \% \mathrm{CE} \% \mathrm{~B} \% \mathrm{CE} \% \mathrm{BD} \% \mathrm{CE} \% \mathrm{BF} \% \mathrm{CF} \% 85 \% \mathrm{\% C} \% 93 \% \mathrm{CE} \% \mathrm{AC} \% \mathrm{CE} \% \mathrm{BB} \% \mathrm{CE} \% \mathrm{~B} 1 \% \mathrm{CE} \% \mathrm{BA} \% \mathrm{CF} \% 84 \% \mathrm{CE} \% \mathrm{BF} \%$ CF\%82_2019.pdf (accessed on 20 December 2020).

2. Pulina, G.; Milan, M.J.; Lavin, M.P.; Theodoridis, A.; Morin, E.; Capote, J.; Thomas, D.L.; Francesconi, A.H.D.; Caja, G. Current production trends, farm structures, and economics of the dairy sheep and goat sector. J. Dairy Sci. 2018, 101, 6715-6729. [CrossRef]

3. Muehlherr, J.E.; Zweifel, C.; Corti, S.; Blanco, J.E.; Stephan, R. Microbiological quality of raw goat's and ewe's bulk-tank milk in Switzerland. J. Dairy Sci. 2003, 86, 3849-3856. [CrossRef] 
4. Rola, J.G.; Sosnowski, M.; Ostrowska, M.; Osek, J. Prevalence and antimicrobial resistance of coagulase-positive staphylococci isolated from raw goat milk. Small Rumin. Res. 2015, 123, 124-128. [CrossRef]

5. $\quad$ Lianou, D.T.; Michael, C.K.; Vasileiou, N.G.C.; Petinaki, E.; Cripps, P.J.; Tsilipounidaki, K.; Katsafadou, A.I.; Politis, A.P.; Kordalis, N.G.; Ioannidi, K.S.; et al. Extensive countrywide field investigation of somatic cell counts and total bacterial counts in bulk tank raw milk in goat herds in Greece. J. Dairy Res. 2021, 88, 307-313. [CrossRef]

6. Altaf, M.; Ijaz, M.; Iqbal, M.K.; Rehman, A.; Avais, M.; Ghaffar, A.; Ayyub, R.M. Molecular characterization of methicillin resistant Staphylococcus aureus (MRSA) and associated risk factors with the occurrence of goat mastitis. Pak. Vet. J. 2020, 40, 1-6.

7. Caruso, M.; Latorre, L.; Santagada, G.; Fraccalvieri, R.; Miccolupo, A.; Sottili, R.; Palazzo, L.; Parisi, A. Methicillin-resistant Staphylococcus aureus (MRSA) in sheep and goat bulk tank milk from Southern Italy. Small Rumin. Res. 2016, 135, 26-31. [CrossRef]

8. Lira, M.C.; Givisiez, P.E.N.; de Sousa, F.G.C.; Magnani, M.; de Souza, E.L.; Spricigo, D.A.; Gebreyes, W.A.; Wondwossen, A.; de Oliveira, C.J.B. Biofilm-forming and antimicrobial resistance traits of staphylococci isolated from goat dairy plants. J. Inf. Dev. Ctries 2016, 10, 932-938. [CrossRef] [PubMed]

9. Obaidat, M.M.; Roess, A.A.; Mahasneh, A.A.; Al-Hakimi, R.A. Antibiotic-resistance, enterotoxin gene profiles and farm-level prevalence of Staphylococcus aureus in cow, sheep and goat bulk tank milk in Jordan. Int. Dairy J. 2018, 81, 28-34. [CrossRef]

10. European Union. Regulation (EC) No. 853/2004 of the European Parliament and of the Council of 29 April 2004 laying down specific hygiene rules foron the hygiene of foodstuffs. Off. J. Eur. Union 2004, L 139/55.

11. Andreoletti, O.; Baggesen, D.L.; Bolton, D.; Butaye, P.; Cook, P.; Davies, R.; Escamez, P.S.F.; Griffin, J.; Hald, T.; Havellar, A.; et al. Scientific opinion on the public health risks related to the consumption of raw drinking milk. EFSA J 2015, $13,3940$.

12. Virdis, S.; Scarano, C.; Cossu, F.; Spanu, V.; Spanu, C.; De Santis, E.P.L. Antibiotic Resistance in Staphylococcus aureus and coagulase negative staphylococci isolated from goats with subclinical mastitis. Vet. Med. Int. 2010, 2010, 517060. [CrossRef]

13. Koop, G.; De Visscher, A.; Collar, C.A.; Bacon, D.A.C.; Maga, E.A.; Murray, J.D.; Supre, K.; De Vliegher, S.; Haesebrouck, F.; Rowe, J.D.; et al. Identification of coagulase-negative staphylococcus species from goat milk with the API Staph identification test and with transfer RNA-intergenic spacer PCR combined with capillary electrophoresis. J. Dairy Sci. 2012, 95, 7200-7205. [CrossRef]

14. Michael, C.K.; Lianou, D.T.; Vasileiou, N.G.C.; Tsilipounidaki, K.; Katsafadou, A.I.; Politis, A.I.; Kordalis, N.G.; Ioannidi, K.S.; Gougoulis, D.A.; Trikalinou, C.; et al. Association of staphylococcal populations on teatcups of milking rarlours with vaccination against staphylococcal mastitis in sheep and goat farms. Pathogens 2021, 10, 385. [CrossRef]

15. Anderson, K.L.; Kearns, R.; Lyman, R.; Correa, M.T. Staphylococci in dairy goats and human milkers, and the relationship with herd management practices. Small Rumin. Res. 2019, 171, 13-22. [CrossRef]

16. Verhoeven, P.O.; Gagnaire, J.; Botelho-Nevers, E.; Grattard, F.; Carricajo, A.; Lucht, F.; Pozzetto, B.; Berthelot, P. Detection and clinical relevance of Staphylococcus aureus nasal carriage: An update. Expert Rev. Anti-Infect. Ther. 2014, 12, 75-89. [CrossRef]

17. Vasileiou, N.G.C.; Sarrou, S.; Papagiannitsis, C.; Chatzopoulos, D.C.; Malli, E.; Mavrogianni, V.S.; Petinaki, E.; Fthenakis, G.C. Antimicrobial agent susceptibility and typing of staphylococcal isolates from subclinical mastitis in ewes. Microb. Drug. Res. 2019, 25, 1099-1110. [CrossRef]

18. Mavrogianni, V.S.; Menzies, P.I.; Fragkou, I.A.; Fthenakis, G.C. Principles of mastitis treatment in sheep and goats. Vet. Clin. N. Am. Food Anim. Pract. 2011, 27, 115-120. [CrossRef]

19. Koulenti, D.; Fragkou, P.C.; Tsiodras, S. Editorial for Special Issue 'Multidrug-Resistant Pathogens'. Microorganisms 2020, 8, 1383. [CrossRef]

20. Hellenic Veterinary Association. European Day for Information and Awareness for the Use of Antibiotics. Press release (ref. 1631, 15 Nov. 2018), Athens, 2018.

21. Wassenaar, T.M.; Ussery, D.; Nielsen, L.N.; Ingmer, H. Review and phylogenetic analysis of qac genes that reduce susceptibility to quaternary ammonium compounds in Staphylococcus species. Eur. J. Microbiol. Immunol. 2015, 5, 44-61. [CrossRef]

22. Slifierz, M.J.; Friendship, R.M.; Weese, J.S. Methicillin-resistant Staphylococcus aureus in commercial swine herds is associated with disinfectant and zinc usage. Appl. Environ. Microbiol. 2015, 81, 2690-2695. [CrossRef]

23. Templeton, M.R.; Oddy, F.; Leung, W.K.; Rogers, M. Chlorine and UV disinfection of ampicillin-resistant and trimetoprim-resistant Escherichia coli. Can. J. Civ. Eng. 2009, 36, 889-894. [CrossRef]

24. Khan, S.; Beattie, T.; Knapp, C. Relationship between antibiotic- and disinfectant-resistance profiles in bacteria harvested from tap water. Chemosphere 2016, 152, 132-141. [CrossRef]

25. Sidhu, M.S.; Heir, E.; Leegaard, T.; Wiger, K.; Holck, A. Frequency of disinfectant resistance genes and genetic linkage with beta-lactamase transposon Tn552 among clinical staphylococci. Antimicrobal Agents Chemother. 2002, 46, 2797-2803. [CrossRef]

26. Russell, A.D. Do biocides select for antibiotic resistance? J. Pharm. Pharmacol. 2000, 52, 227-233. [CrossRef]

27. Deng, W.; Quan, Y.; Yang, S.Z.; Guo, L.J.; Zhang, X.L.; Liu, S.L.; Chen, S.J.; Zhou, K.; He, L.; Li, B.; et al. Antibiotic resistance in salmonella from retail foods of animal origin and its association with disinfectant and heavy metal resistance. Microb. Drug Res. 2018, 24, 782-791. [CrossRef]

28. Yarwood, J.M.; McCormick, J.K.; Paustian, M.L.; Kapur, V.; Schlievert, P.M. Repression of the Staphylococcus aureus accessory gene regulator in serum and in vivo. J. Bacteriol. 2002, 184, 1095-1101. [CrossRef]

29. Malachowa, N.; DeLeo, F.R. Mobile genetic elements of Staphylococcus aureus. Cell. Mol. Life Sci. 2010, 18, 3057-3071. [CrossRef]

30. Shearer, J.E.S.; Wireman, J.; Hostetler, J.; Forberger, H.; Borman, J.; Gill, J.; Sanchez, S.; Mankin, A.; LaMarre, J.; Lindsay, J.A.; et al Major families of multiresistant plasmids from geographically and epidemiologically diverse staphylococci. Gen. Genom. Genet. 2011, 1, 581-591. [CrossRef] 
31. Allen, H.K.; Trachsel, J.; Looft, T.; Casey, T.A. Finding alternatives to antibiotics. Antimicrob. Ther. Rev. Inf. Dis. Curr. Emerg. Conc. 2014, 1323, 91-100. [CrossRef]

32. Heinz, D. Farm workers contracting drug-resistant bacteria, study shows. Healthline 2013. Available online: https://www. healthline.com/health-news/public-farmhands-develop-antibiotic-resistance-070613 (accessed on 26 August 2021).

33. Lianou, D.T.; Chatziprodromidou, I.P.; Vasileiou, N.G.C.; Michael, C.K.; Mavrogianni, V.S.; Politis, A.P.; Kordalis, N.G.; Billinis, C.; Giannakopoulos, A.; Papadopoulos, E.; et al. A detailed questionnaire for the evaluation of health management in dairy sheep and goats. Animals 2020, 10, 1489. [CrossRef] [PubMed]

34. Laird, D.T.; Gambrel-Lenarz, S.A.; Scher, F.M.; Graham, T.E.; Reddy, R. Microbiological Count Methods. In Standard Methods for the Examination of Dairy Products, 17th ed.; Wehr, H.M., Frank, J.F., Eds.; APHA Press: Washington, DC, USA, 2004 ; pp. 153-186.

35. Barrow, G.I.; Feltham, R.K.A. Manual for the Identification of Medical Bacteria, 3rd ed.; Cambridge University Press: Cambridge, UK, 1993.

36. Euzeby, J.P. List of bacterial names with standing in nomenclature: A folder available on the Internet. Int. J. Syst. Bacteriol. 1997, 47, 590-592. [CrossRef] [PubMed]

37. Vasileiou, N.G.C.; Chatzopoulos, D.C.; Gougoulis, D.A.; Sarrou, S.; Katsafadou, A.I.; Spyrou, V.; Mavrogianni, V.S.; Petinaki, E.; Fthenakis, G.C. Slime-producing staphylococci as causal agents of subclinical mastitis in sheep. Vet. Microbiol. 2018, 224, 93-99. [CrossRef]

38. Magiorakos, A.P.; Srinivasan, A.; Carey, R.B.; Carmeli, Y.; Falagas, M.E.; Giske, C.G.; Harbarth, S.; Hindler, J.F.; Kahlmeter, G.; Olsson-Liljequist, B.; et al. Multidrug-resistant, extensively drug-resistant and pandrug-resistant bacteria: An international expert proposal for interim standard definitions for acquired resistance. Clin. Microbiol. Infect. 2012, 18, 268-281. [CrossRef] [PubMed]

39. Wiggans, G.R.; Shook, G.E. A lactation measure of somatic cell count. J. Dairy Sci. 1987, 70 (Suppl. 13), 2666-2672. [CrossRef]

40. Franzoi, M.; Manuelian, C.L.; Penasa, M.; De Marchi, M. Effects of somatic cell score on milk yield and mid-infrared predicted composition and technological traits of Brown Swiss, Holstein Friesian, and Simmental cattle breeds. J. Dairy Sci. 2020, 103, 791-804. [CrossRef]

41. Wang, H.; McEntire, J.C.; Zhang, L.; Li, X.; Doyle, M. The transfer of antibiotic resistance from food to humans: Facts, implications and future directions. Rev. Sci. Tech. (Int. Off. Epizoot.) 2012, 31, 249-260. [CrossRef]

42. Schwarz, S.; Loeffler, A.; Kadlec, K. Bacterial resistance to antimicrobial agents and its impact on veterinary and human medicine. Vet. Dermatol. 2017, 28, 82-e19. [CrossRef] 